\title{
Study of Soil Erosion around an Island in a Natural Stream
}

\author{
[ Snigdhadip Ghosh and Vijay Kumar Dwivedi ]
}

\begin{abstract}
As per Government of India, India is losing 5,334 million tonnes of soil every year due to soil erosion [The Hindu, Nov 26, 2010]. Another survey says soil erosion in India estimated to be occurring on 147 million hectares of land including 94 mha from water erosion, 16 mha from acidification, 14 mha from flooding, 9mha from wind erosion, and $7 \mathrm{mha}$ from a combination of factors. [R. Bhattacharya, Sustainability 2015, 7].
\end{abstract}

In this study based on mobile river bed setup, plan form development around an island and corresponding soil erosion and deposition are evaluated. Directional current (DCM) and acoustic Doppler Velocity (ADV) meters are used for the field measurements of velocity and turbulence particularly in the interface region between main channel and floodplain. The values of local shear velocity and roughness length for the reach under study being calculated and analyzed using measured velocity data in order to provide a scientific pattern of plan form development. Measurements are carried out through different steps. Such as, Measurement of Discharge by Electronic Flow Meter, Discharge measurement using $\mathrm{V}$ Notch, Measurement for the Velocity Distribution with the help of ADV, The value of dry density are computed by using the observed value of bulk density and antecedent moisture content. The void ratio was derived from the computed value of dry density of the sediments.

[Keywords: Plan form development, Soil erosion, DCM, ADV, Shear velocity]

\section{Introduction}

The U.S. Geological Survey (USGS) operates a network of more than 7,200 stream flow-gauging stations in the United States (Wahl and others, 1995) for the production of continuous records of stream and river discharge. The USGS annually publishes the record from each streamflow-gauging station as mean daily discharge values and provides real-time discharge data from more than 4,200 stream flow gauging stations (Wahl and others, 1995).In alluvial sand-bed rivers, bed forms often are present on the bed. These bed forms are complex and dynamic, and appreciably affect the overall flow field. The flow over a field of bed forms, such as dunes, is more complex than in plane-bed situations. The dunes are an obstacle to the flow and cause both wake effects downstream of the dune and topographically induced spatial acceleration of the flow. The prime objective of this research is to study detachment, transport and deposition of cohesion less uniform and non-uniform sediment around an island in a natural stream so that flow process around the Island can be predicted and erosion of the Island can be arrested. The specific objectives of proposed investigation are:

1. To study of development of bed plan form due to presence of an island in a natural stream

2. To identify velocity $\&$ vector field around an island in a natural stream.

\section{Literature review}

The concept of critical friction velocity or critical bed shear stress has long occupied a central position in sediment transport theory. Several investigations related to critical shear stress of uniform and nonuniform sediments in the absence of cohesion are available. An extensive review of different approaches for the computation of critical shear stress has been done by Grade and Ranga Raju (2000).

Critical shear stress of uniform cohesionless sediments has been studied by several authors. However the criterion developed by Shields (1936); Yalin and Karahan (1979) are used most frequently for the computation of critical shear stress of uniform cohesionless sediments.

Egiazaroff (1965) proposed the methods to calculate critical shear stress for size fraction $d$ of a
Dr. Vijay Kumar Dwivedi (Author)

National Institute of Technology Durgapur India
National Institute of Technology Durgapur India 
sediment mixture as a function of $d_{i} / d_{a}^{\prime}$ and critical shear stress $\tau_{c a}$ for the arithmetic mean size $d_{a}^{\prime}$. However they did not propose any predictor for $\tau_{c a}$. Here $d_{i}$ is the particle size, ${ }^{d}{ }_{a}^{\prime}$ is the arithmetic mean size of sediment mixture and $\tau_{c a}$ is the critical shear stress for arithmetic mean size. Parker et al. (1982), Eilcock and Southhard (1988) proposed the concept of equal mobility for the sediment particles in a mixture. They related the critical shear stress for size $d_{i}$ with $d_{i} / d_{50}$ and critical shear stress $\tau_{c 50}$ for the median size $d_{50}$. They also proposed a predictor for $\tau_{c 50}$. Wiberg and Smith (1987), Komar and Li (1988), James (1990); Bridge and Bennett (1992) proposed semianalytical models to calculate the critical shear stress based on balance of forces or moment on an individual particle resting on a bed of nonuniform sediments. They found that critical shear stress of a particular size fraction depends upon the angle of repose of sediment particle and relative protrusion of the grain into flow. However these models involve the use of a number of empirical coefficients which are required to be known apriori.

Patel and Ranga Raju (1999) carried out extensive experiments on initiation of motion and bed load transport of different fractions of sediment mixtures. They checked the accuracy of different models viz; Egiazaroff (1965), Ashida and Michiue (1971), Hayashi et al. (1980), Parker et al. (1982), Wiberg and Smith (1987); Bridge and Bennett (1992). Since the available methods did not produce satisfactory results, Patel and Ranga Raju (1999) proposed a new relationship for critical shear stress of different fractions in a mixture as

$$
\frac{\tau_{*_{c i}}}{\tau_{*_{c \sigma}}}=\left(\frac{d_{i}}{d \sigma}\right)^{-0.96}
$$

Here $d_{\sigma}=\sigma_{g} d_{g}$ is geometric mean size of the mixture, $\sigma_{g}$ is its geometric standard deviation, $\tau_{c i}$ is the dimensionless critical shear stress for size ${ }^{d_{i}}, \tau_{* c \sigma}$ is the dimensionless critical shear stress for size $d_{\sigma}$. They also proposed a graphical relationship between $\tau_{*_{c \sigma} \text { and }} \sigma_{g}$.

\section{Details of experimental set up}

\section{A. Flume}

The experiments were conducted in the experimental setup created at National Institute of Technology, Durgapur. The setup consists of a flume $20 \mathrm{~m}$ long, $4 \mathrm{~m}$ wide and $10 \mathrm{~m}$ deep. The flume has a cemented bottom and glass wall on both side with a grid of $5 \times 5 \mathrm{~cm}$ up to a height of $50 \mathrm{~cm}$ from the bottom of the flume to measure the bed profile. Experiments were done at several slopes of bed in the flume. The discharge in the flume will be provided by a upstream reservoir feed by two 10" mild steel pipes. There are two pumps of 7.5 HP each to supply water to the MS pipe from the underground reservoir. The water supply into flume was regulated with the help of a valve provided in the inlet pipe coming from reservoir. The water from the flume was drained to the reservoir through an escape channel, $41.2 \mathrm{~m}$ long, $1 \mathrm{~m}$ wide and $0.6 \mathrm{~m}$ deep. Its discharge to the channel was volumetrically measured with the help of another tank provided at the downstream end of the channel. The water level and discharge through the flume were controlled by a motor operated sluice gate at the tailed end of the flume. Experimental soil is collected locally and analyzed. The sludge velocity instrument is Sontek Accoustic doppler velocimeter. ADV can measure three dimensional point velocities and turbulence parameters in shallow and deep water system in nearly any location in the water column and close to boundaries as long as air entertainment is minimal.

\section{Methodology and Measurements}

\section{A. Discharge measurement using V Notch}

Two $90^{\circ}$ V-Notch have been installed in the escape channel to measure discharge in the flume. The installed V-Notch has been calibrated with the help of Electronic Flow meter.

\section{B. Measurement for the Velocity Distribution}

The velocity profile along the centrelines of the flume width in the approach flow was measured with the help of Acoustics Doppler Velocity meter (ADV). Acoustic Doppler Velocity Meter is a versatile, high-precision instrument used to measure water velocity in a wide range of environments including laboratories, rivers, estuaries, and the ocean. The instrument consists of three basic elements: the probe, the signal conditioning module, and the processor. The probe is attached to the conditioning module, which contains low noise receiver enclosed in a submersible housing. The ADV conditioning module and probe are connected to the processing module using a custom shielded cable up to 
10-m long. The ADV uses acoustic Doppler technology to measure flow in a small sampling volume located 5 $\mathrm{cm}$ from the probe. The velocity range is programmable from \pm 3 to $\pm 250 \mathrm{~cm} / \mathrm{s}$, Data can be acquired at sampling rates up to $50 \mathrm{~Hz}$. with no zero offset, measured flow velocities from less than $1 \mathrm{~mm} / \mathrm{s}$ to over $2.5 \mathrm{~m} / \mathrm{s}$.

\section{Measurements of Dry Density}

The values of dry density were computed by using the observed value of bulk density and antecedent moisture content. The void ratio was derived from the computed value of dry density of the sediments.

\section{Sediment Load Measurements}

The sediment transported as bed load was collected in a trap placed at the downstream end of downstream end of the flume just before the tail gate location. The samples of sediments water mixture was collected in containers by traversing the depth integrating sampler over the entire width of flow. The containers were weighed to determine the weight of water-sediment mixture in them. The water was removed next from these containers after allowing the fine sediment to settle completely which requires 24 hours time. Next the sediments was removed from these containers using filters into smaller size pans and these pans will be keep in an electric oven for drying. After drying the samples, the weight of suspended sediments were measured by using an electronic balance having a least count of $0.01 \mathrm{~g}$. The concentration of suspended sediment sampled in each container now determine the concentration of suspended sediment by dividing the weight of sediment contained by the given volume/weight of water.

\section{Experimental procedure}

After spreading the desired sediments in the flume, the bed surface will be smoothened with the help of a wooden template by moving it from upstream to downstream. A hemispherical island of the same bed material would be created in the middle of the flume. Thus a mobile bed with an island on the bed would be ready for the run of the experiment. The water then will be admitted in to the flume first at a very low discharge. Velocity vectors at different spatial locations would be measured with the help of ADV. Bed load measurement will be taken at regular interval. Suspended load samples would be taken in the beginning of the flow and at the instant when flow has stabilized. Water surface profile as well as bed surface profile will be measured at regular interval along transverse and longitudinal interval along the flume. These water and bed surface profiles will be measured at regular time interval.

\section{A. ADV Components, Terminology and Sampling}

SonTek Acoustic Doppler Velocimeter (ADV) systems are two types .Field systems or Lab systems. ADV Field systems can be of three types .splash-proof, underwater, or autonomous (Hydra) systems. The hardware for these systems is composed of two main components: signal processing hardware and probe hardware. The signal processing hardware can be contained in a splash-proof housing or an underwater canister. The probe hardware can be of three basic types: a $16-\mathrm{MHz}$ Micro ADV probe, a $10-\mathrm{MHz}$ ADV probe, or a 5-MHz ADV Ocean probe. The signal processing hardware performs the signal generation and processing required for the ADV to make velocity measurements. This includes generating the electrical signals that are converted to acoustic energy at the transducers, digitizing the return signal, performing Doppler processing to calculate velocity, and averaging samples together before data output. The applicability of turbulence measurements by using ADV in actual rivers and laboratory flumes were verified by many researchers (e.g. Nikora \& Goring 2000, Kim et al. 2000, Song \& Chiew 2001, Storm \& Papanicolaou 2007). It was also proved in the study that the velocity measurements using ADV are reasonably accurate and the turbulence structures have consistency even in these non-uniform flow fields.

\section{Data collection and comparison:}

Image I: Orientation of stations.

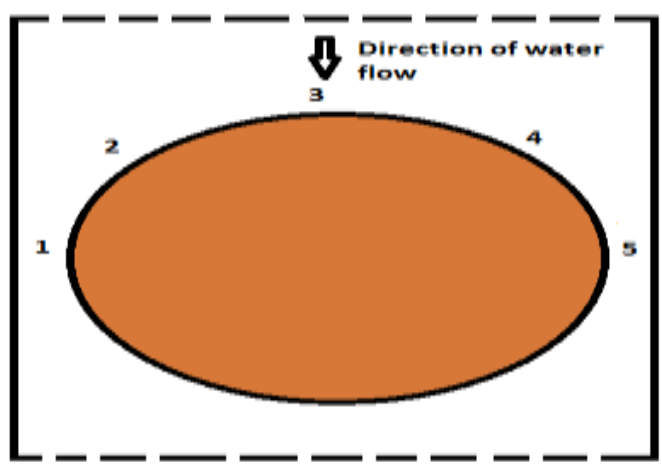

- $\quad$ Reading I

Mode of ADV: Discharge mode.

Discharge Rate: $0.121 \mathrm{~m}^{3} / \mathrm{Sec}$

Date of test: February 1, 2016

Table I: Data recorded on February 1, 2016 
Proc. of Sixth International Conference On Advances in Civil, Structural and Mechanical Engineering -ACSM 2017 Copyright (C) Institute of Research Engineers and Doctors, USA .All rights reserved.

ISBN: 978-1-63248-118-4 doi: 10.15224/ 978-1-63248-118-4-23

\begin{tabular}{|l|l|l|l|l|l|l|}
\hline $\begin{array}{l}\text { Statio } \\
\mathbf{n}\end{array}$ & $\begin{array}{l}\text { Velocit } \\
\mathbf{y}\end{array}$ & $\begin{array}{l}\text { Seepage } \\
\text { velocity }\end{array}$ & $\begin{array}{l}\text { Angl } \\
\text { e }\end{array}$ & $\begin{array}{l}\text { S.N. } \\
\text { R. }\end{array}$ & $\begin{array}{l}\text { Spik } \\
\text { e }\end{array}$ & $\begin{array}{l}\text { Ban } \\
\text { d }\end{array}$ \\
\hline 1 & 0 & 0 & -72 & 31.1 & 0 & good \\
\hline 2 & 0.025 & 0.009 & -15 & 33.7 & 2 & best \\
\hline 3 & 0.227 & 0.103 & 15 & 5.7 & 0 & best \\
\hline 4 & 0.096 & 0.124 & 122 & 7.9 & 0 & best \\
\hline 5 & 0.001 & 0.003 & 131 & 27.5 & 1 & best \\
\hline
\end{tabular}

\begin{tabular}{|l|l|l|l|l|l|l|}
\hline $\begin{array}{l}\text { Statio } \\
\mathbf{n}\end{array}$ & $\begin{array}{l}\text { Velocit } \\
\mathbf{y}\end{array}$ & $\begin{array}{l}\text { Seepage } \\
\text { velocity }\end{array}$ & $\begin{array}{l}\text { S.N. } \\
\text { R. }\end{array}$ & $\begin{array}{l}\text { Angl } \\
\mathbf{e}\end{array}$ & $\begin{array}{l}\text { Spik } \\
\mathbf{e}\end{array}$ & $\begin{array}{l}\text { Ban } \\
\mathbf{d}\end{array}$ \\
\hline 1 & 0.015 & 0.005 & 21.5 & -72 & 0 & good \\
\hline 2 & 0.007 & 0.003 & 17.7 & -12 & 2 & good \\
\hline 3 & 0.029 & 0.005 & 19.7 & 11 & 2 & best \\
\hline 4 & 0.79 & 0.002 & 17.6 & 37 & 0 & best \\
\hline 5 & 0.017 & 0.002 & 27.1 & 82 & 0 & best \\
\hline
\end{tabular}

Where SNR is signal to noise ratio and spike is the sharp increment in the magnitude or concentration of Doppler in the corresponding stations around the island.

Figure I: Variation of velocity depending on reading I

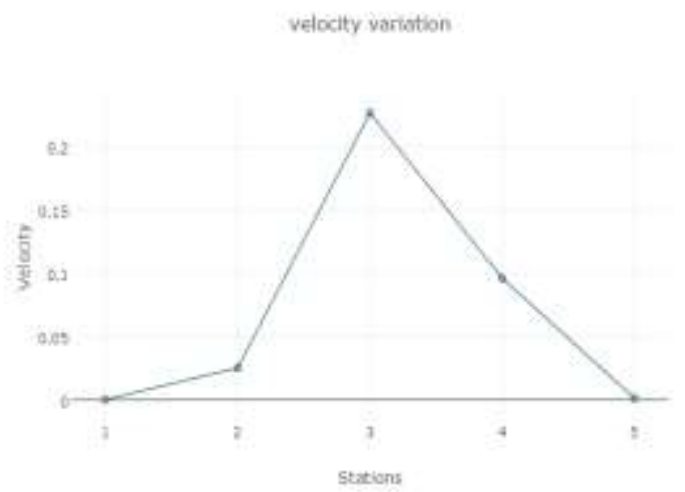

Figure II: Variation of Seepage velocity depending on reading I

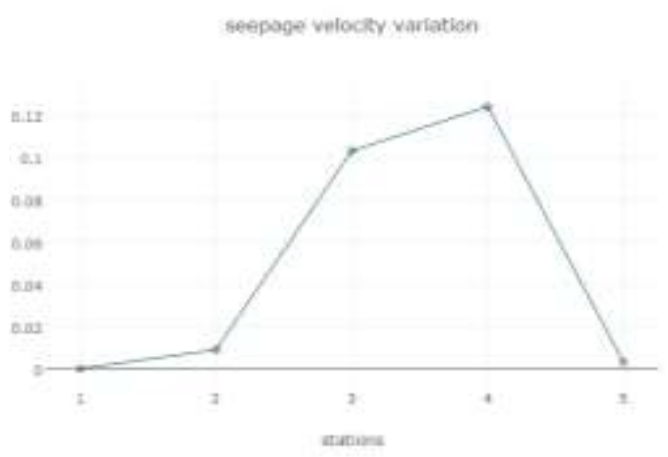

- $\quad$ Reading II

Mode of ADV: Discharge mode.

Discharge rate: $0.121 \mathrm{~m}^{3} / \mathrm{sec}$

Date of test: February 5, 2016

Table II: Data recorded on February 5, 2016

Figure III: Variation of velocity depending on reading II velocity variation

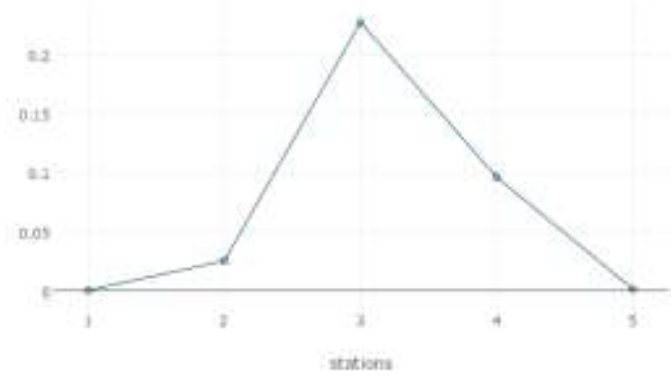

Figure IV: Variation of velocity depending on reading II

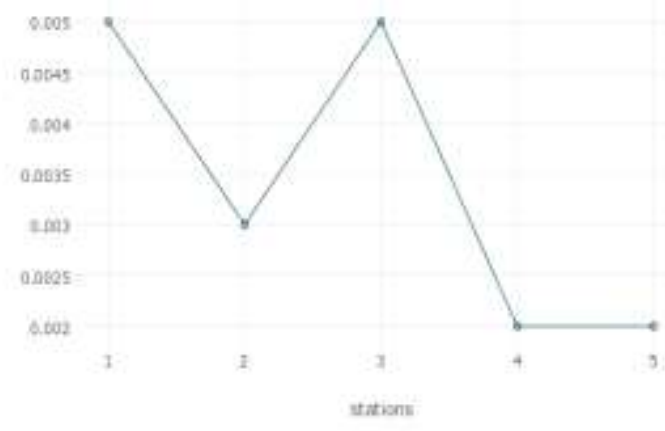

VII. Conclusion

The pattern of sediment velocity observed in two consecutive experiment data with the help of micro Accoustic Doppler Velocimeter was that the velocity of sediment particles increased at station 3 and 4 as the direction of current was directly towards the stations whereas there were angular velocities in station 1 and 5 . SNR values were inversely proportional to the velocity of settling particles. The difference between day 1 experiment data and day 2 experiment data was mainly because of the consolidation and degree of saturation of 
island, though the pattern of erosion and deposition were almost same.

\section{References}

[1] Almedeij, J. H., and Diplas, P. 2003. "Bed load transport in gravel-bed streams with unimodal sediment." J. Hydraul. Eng., 12911, 896- 904.

[2] Biron, P. M., S. N. Lane, A. G. Roy, K. F. Bradbrook, and K. S. Richards (1998), Sensitivity of bed shear stress estimated from the vertical velocity profiles: The problem of sampling resolution, Earth Surf. Processes Landforms, 23, 133-139.

[3] Borah, D. K., Alonso, C. V., and Prasad, S. N. 1982. "Routing of graded sediments in streams: Formulations." J Hydraul. Eng., 10812, 1486-1503.

[4] Carling, P.A., Cao, Z., Ervine, D.A. and BabaeyanKoopaei, K. (2002). Turbulent flow across a natural compound river chan-nel. J. Water Resour. Res. (Paper No. 10.1029/2001 WR 00902, Dec. 2002).

[5] Kikkawa, H., and Fukuoka, S. 1969. "The characteristics of flow with wash load." Proc., 13th Cong. IAHR, Vol. 2, 233-240.

[6] Khullar, N. K., Kothyari, U. C., and Ranga Raju, K. G. 2007. "Effect of wash load on sediment on flow resistance." J. Hydraul. Res., 454, 497-504.

[7] Kostaschuk, R., J. Best, P. Villard, J. Peakall, and M. Franklin (2005), Measuring flow velocity and sediment transport with an acoustic Doppler current profiler, Geomorphology, 68, 25-37.

[8] Lane, E. W. 1947. "Report of the subcommittee on sediment terminology." Trans., Am. Geophys. Union, 28.

[9] Misri, R. L., Ranga Raju, K. G., and Garde, R. J. 1984 "Bed load transport of coarse nonuniform sediments." J Hydraul. Eng., 1103, 312-328.

[10] Morvan, H. (2001). Three dimensional modeling of rivers, $\mathrm{Ph} . \mathrm{D}$. Thesis, University of Glasgow, Glasgow, UK

[11] Morvan, H., Pender, G., Wright, N.G. and Ervine, D.A. (2002). Three dimensional hydrodynamics of meandering compound flows, in Proc. ASCE, J. Hydraul. Eng., 128(7), 674-682.

[12] Rennie, C. D., R. G. Millar, and M. A. Church (2002), Measurement of bed load velocity using an acoustic Doppler current profiler, J. Hydraul.Eng., 128, 473- 483.

[13] Shields, F. D., and J. R. Rigby (2005), River habitat quality from river velocities measured using acoustic Doppler current profiler, Environ. Manage., 36, 565- 575.
[14] Whiting, P., and W. E. Dietrich (1991), Boundary shear stress and roughness over mobile alluvial beds, J. Hydaul. Eng. Am. Soc. Civ. Eng., 116, 1495-1511.

[15] Wu, W., Wang, S. Y., and Jia, Y. 2000. "Nonuniform sediment transport in alluvial rivers.” J. Hydraul. Eng., 386, 427-434.

[16] Yorke, T. H., and K. A. Oberg (2002), Measuring river velocity and discharge with acoustic Doppler profilers, Flow Meas. Instrum., 13, 191-195.

About Author (s):

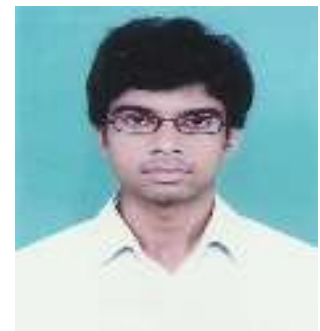

Snigdhadip Ghosh was born in Birbhum, West Bengal, India, in 1989. Hereceived the B.Tech degree in Civil Engineering from West Bengal University of Technology India, in 2011, and the M.Tech. degree in Soil \&amp; Water Engineering from Bidhan Chandra Krishi Viswavidyalaya, Nadia, West Bengal in 2013. Since 2013, he has been with the Institute of Engineering \&amp; Industrial Technology,Durgapur, as an assistant professor. Currently he works as a research scholar of Water resourceEngineering Laboratory, National Institute of Technology, Durgapur (NITD)

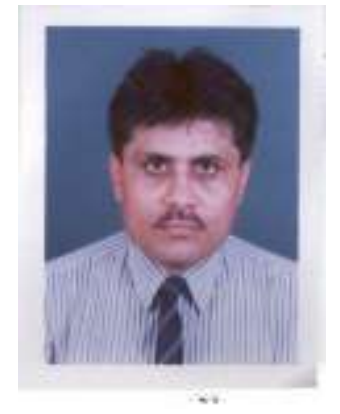

Prof. Vijay Kumar Dwivedi a Doctorate Degree in Civil Engineering (Hydrology) with Master's in Civil Engineering (Water Resources Engg.), Bachelor in Civil Engineering and has expertise in the field of applied and basic hydrology, water resource management for more than 28 years. Prof. Dwivedi is currently working as a Full Time Professor in the Department of Civil Engineering of National Institute of Technology Durgapur, India. He has been the Principal Investigator for several hydrological projects, water resources \& storm water projects and have been responsible for perception, formulation, planning, design, execution of the project and implementation of the research findings. 